\title{
Vibrations of the TAIPEI 101 Skyscraper Induced by Typhoon Fanapi in 2010
}

\author{
Kou-Cheng Chen *, Jeen-Hwa Wang, Bor-Shouh Huang, Chun-Chi Liu, \\ and Win-Gee Huang
}

Institute of Earth Sciences, Academia Sinica, Taipei, Taiwan

Received 29 September 2011, accepted 17 September 2012

\begin{abstract}
The TAIPEI 101 skyscraper (508-m) is comprised of 101 floors above ground and five floors below ground. It is located in the Hsinyi District of Taipei, Taiwan. The skyscraper is equipped with a 660-metric-ton tuned mass damper - the largest of its type in the world. Both the skyscraper and the tuned mass damper swayed during Typhoon Fanapi on 19 September 2010. Maximum vertical, E-W, and N-S displacements measured on the $90^{\text {th }}$ floor were approximately $0.26,4.71$, and $9.04 \mathrm{~cm}$, respectively. The spectra of three-component seismograms recorded at the $74^{\text {th }}$ and $90^{\text {th }}$ floors above ground and the fifth floor underground are analyzed. Fundamental and higher mode vibrations, with local peak amplitudes, can be clearly seen on the spectra recordings. The frequency of the fundamental mode is about $0.15 \mathrm{~Hz}$, which is the natural frequency for the skyscraper. The fundamental mode of torsional vibration is at about $0.23 \mathrm{~Hz}$. The vibrations observed are actually the combination of translational and torsional vibrations. The two kinds of vibrations of the TAIPEI 101 skyscraper can be observed and identified either from spectral amplitudes of accelerations or from rotational motions.
\end{abstract}

Key words: Building array, TAIPEI 101, Vibration, Typhoon

Citation: Chen, K. C., J. H. Wang, B. S. Huang, C. C. Liu, and W. G. Huang, 2013: Vibrations of the TAIPEI 101 skyscraper induced by Typhoon Fanapi in 2010. Terr. Atmos. Ocean. Sci., 24, 1-10, doi: 10.3319/TAO.2012.09.17.01(T)

\section{INTRODUCTION}

The three primary concerns for building engineers are structural integrity, the comfort and safety of a building's occupants, and the building's contents. Aside from fire, the foremost threat to all three is vibration. A major cause of building vibration is earthquake-induced ground motions. Chen (2003) reported that a distant earthquake $\left(M_{w} 7.0\right)$ in 2002 caused two massive construction cranes on TAIPEI 101 to fall from the $56^{\text {th }}$ floor to the ground. Other factors include: strong winds, volcanic eruptions, explosions, and landslides. Wind-induced building vibrations were studied by several groups of researchers ( $\mathrm{Li}$ et al. 1998, 2000, 2003, 2004, 2005, 2007; Xu and Zhan 2001; Liu and Tsai 2010). Among those studies, typhoon-induced building vibrations have been observed for the 325-m Di-Wang Tower in Shenzhen, China by Xu and Zhan (2001) and Li et al. (2004), and the 30-story PS Building in Taipei, Taiwan by Liu and Tsai (2010). For the 30-story building, Liu and Tsai (2010) also

\footnotetext{
* Corresponding author

E-mail: chenkc@earth.sinica.edu.tw
}

found that building vibrations caused by the $1999 \mathrm{M}_{\mathrm{s}} 7.6$ Chi-Chi, Taiwan, earthquake were higher than those caused by Typhoon Aere on 20 August 2004. In addition, building vibration can result in the production of seismic $P$ waves as was shown for the landing of the space-shuttle Columbia at Edwards Air Base in 1989. The shock wave caused by the landing of the space shuttle resulted in high-rise buildings vibrating in downtown Los Angeles to the point of producing a seismic $P$ wave that was recorded at the University of Southern California and the IRIS-Terrascope station in Pasadena (Kanamori et al. 1991).

Every year over 10 typhoons occur in western Pacific Ocean regions and Taiwan experiences, on average, more than 4 typhoons yearly (Wang et al. 2005). Typhoons usually cause serious damage in the Taiwan region. The buildings can be influenced by typhoons and strong winds, even though direct damage does not exist. Hence, the studies of typhoon- and strong winds-induced vibrations are an important topic for Taiwan's geoscientists and engineers because there are many high-rise buildings in Taiwan. In this study, the vibration data recorded at the TAIPEI 101 skyscraper 
are analyzed to investigate the effects of typhoon-induced vibrations on this super tall high-rise building.

\section{DATA COLLECTION}

TAIPEI 101 is a skyscraper located in the Hsinyi District of Taipei, Taiwan. It is the second tallest building in the world. The building is comprised of 101 floors above ground and five floors below ground (Haskett et al. 2003; Shieh et al. 2003; Joseph et al. 2006). The height of the main building is $455 \mathrm{~m}$, atop of which is a spire that gives the building a total height of $508 \mathrm{~m}$. The building is equipped with three tuned mass dampers (TMDs) (Haskett et al. 2003). The first is a 660 -metric-ton ball installed between the $87^{\text {th }}$ and $91^{\text {st }}$ floors and observable from public viewing platforms on the $88^{\text {th }}$ and $89^{\text {th }}$ floors. The second and third lesser TMDs are both 4.5 metric tons and provide passive motion dampening in the spire. The TMDs function to reduce vibration caused by earthquakes and typhoons (Haskett et al. 2003). Taiwan is particularly prone to both. Since July 2010, the Institute of Earth Sciences (IES), Academia Sinica has operated a building array at TAIPEI 101, designed to routinely measure building vibration and monitor the effects of typhoonforce winds and earthquakes.

On 19 September 2010, Typhoon Fanapi, a medium strength typhoon generated in the Western Pacific (Fig. 1a), with an eye reaching the south east coast of Taiwan, was one of the strongest typhoons to hit Taiwan in 2010, causing flooding in southern Taiwan and disrupting transportation and power systems in some locations. The typhoon had maximum sustained wind speeds of $162 \mathrm{~km} \mathrm{hr}^{-1}$, gusting up to $198 \mathrm{~km} \mathrm{hr}^{-1}$ (CWB 2010). After passing over the southern end of the island of Taiwan, the typhoon moved into the Taiwan Strait and arrived on the southeast coast of mainland China on September 20. Although the eye of the typhoon was some $300 \mathrm{~km}$ south of Taipei City, it still brought strong winds to the city with peak gusts of $\sim 90 \mathrm{~km} \mathrm{hr}^{-1}$. Only minor damage, however, was reported for northern Taiwan. Wind gusts in Taipei were strong enough to cause both the TAIPEI 101 skyscraper and its main 660-metric-ton TMD to sway.

Building vibrations were continuously recorded by the TAIPEI 101 building array (hereafter TBA). The locations of sensors in the TBA are shown in Fig. 1b. The TBA consists of four stations: two force balance accelerometers (T1S3 and T1S4) (Kinemetrics 2002) are emplaced, respectively, in the northeast and southwest corners of the $90^{\text {th }}$ floor; and two broadband velocity sensors (T1S2 and T1S1) (Hutt et al. 2008) are emplaced in the southwest corner of $74^{\text {th }}$ floor and the fifth floor below ground, respectively. In addition, two $\mathrm{R}-1$ rotational seismometers are emplaced, respectively, on the southwest (T1S3R) and on northeast corners of the $90^{\text {th }}$ floor (T1S4R). All of the stations record signals continuously at 100 and 20 samples per second, respectively. Time synchronization is maintained in the main processor based on time received according to the NTP (network time protocol) through communication with an internet time server. For the two types of seismometers, there is a very broad frequency range of uniform response to external stimuli. The sensitivities of the velocity and acceleration sensors are $2.384 \times 10^{-5} \mathrm{~cm} \mathrm{sec}^{-1}$ count $^{-1}$ and $2.337 \times 10^{-4} \mathrm{~cm} \mathrm{sec}^{-2}$ count $^{-1}$, respectively. The R-1 rotational seismometer has a resolu-

(a)

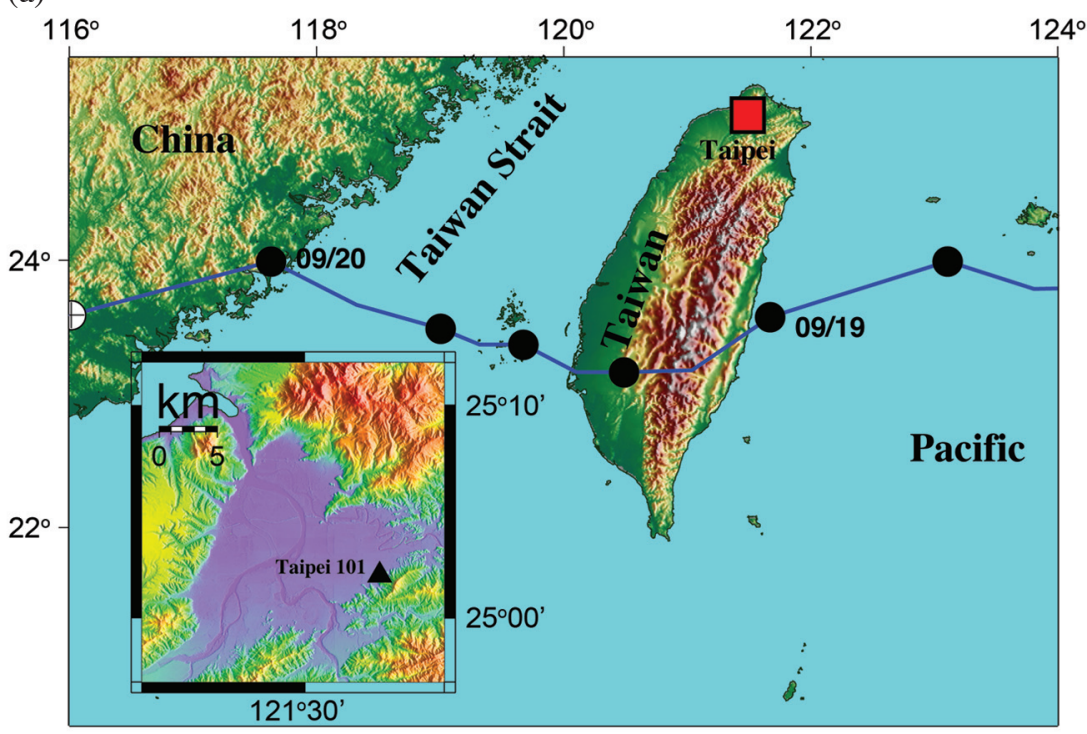

(b)

Fig. 1. (a) Track of the 2010 Typhoon Fanapi (solid line) and locations of typhoon centers (solid circles) per every six hours (CWB 2010). The red square marks the city of Taipei. The insert shows locations of the TAIPEI 101 skyscraper (solid triangle). (b) Locations of sensors in the TAIPEI 101 building array. T1S1 and T1S2 are velocity sensors, T1S3 and T1S4 are accelerometers, and T1S3R and T1S4R are rotational seismometers. 
tion of $1.2 \times 10^{-7} \mathrm{rad} \mathrm{sec}^{-1}$ (eentec 2007).

\section{DATA PROCESSING AND RESULTS}

Continuous three-component records of building vibrations with 20 samples per second recorded at the TBA are analyzed. Figure 2 shows the N-S component records of building vibrations recorded at T1S1, T1S2, T1S3, and T1S4 on 19 September 2010. Vibrations gradually in- crease from 04:00 coordinated universal time (UTC) to 05:00 (UTC) and are then maintained at a strong level until 15:00 (UTC). After which time, vibration begins to subside to background levels. The peak velocity at T1S2 is about two orders of magnitude larger than that at T1S1. The main building's TMD swayed twice: one at about 06:17 (UTC) (labeled "A" in Fig. 2) and the other at 11:53 (UTC) (labeled "B" in Fig. 2) with the latter level of swaying being larger. Maximum peak ground accelerations in the vertical,
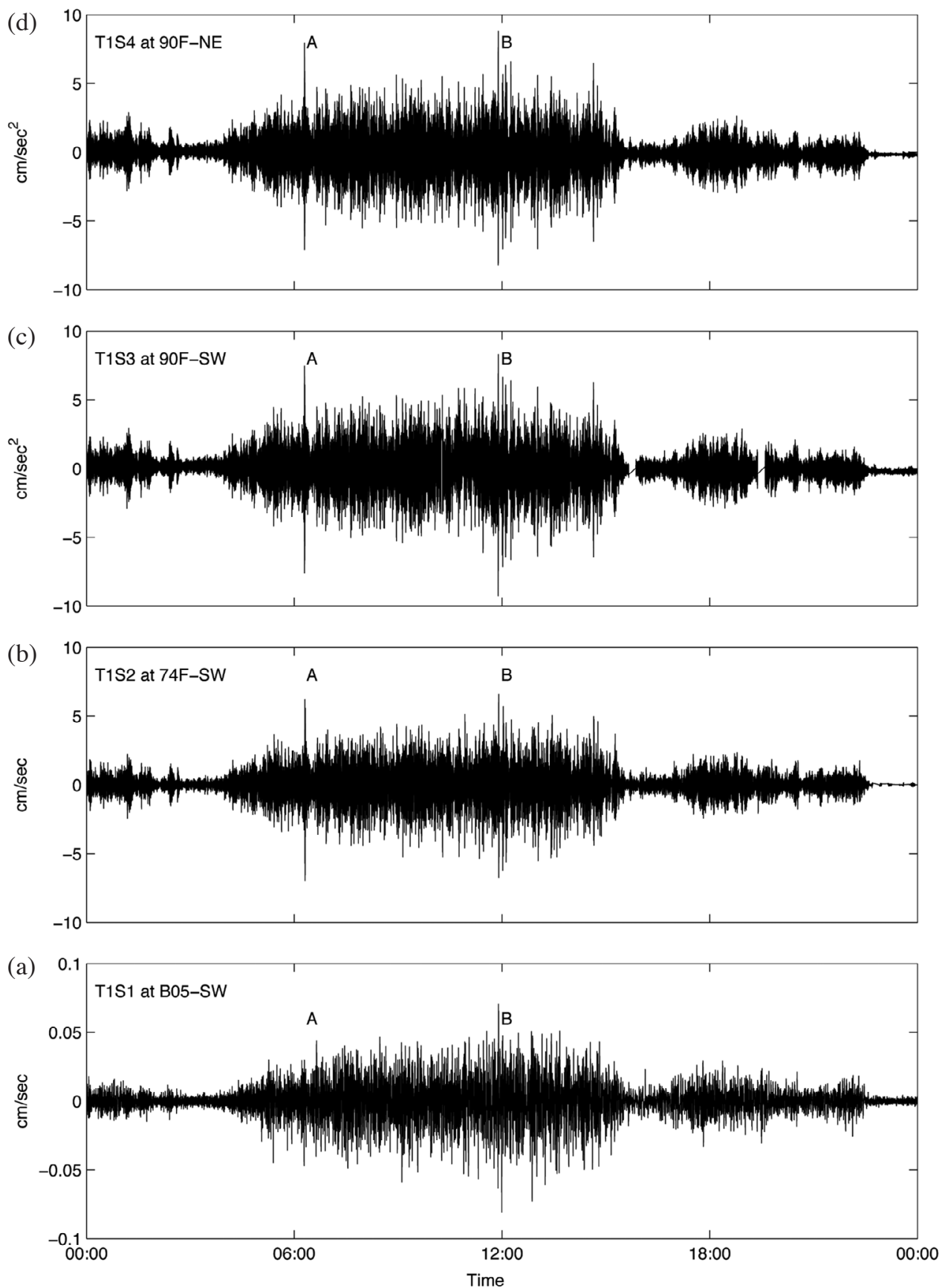

Fig. 2 The N-S component records of building vibrations caused by Typhoon Fanapi: (a) at T1S1 on the fifth floor underground, (b) at T1S2 on the $74^{\text {th }}$ floor, (c) at T1S3 on the $90^{\text {th }}$ floor, and (d) at T1S4 on the $90^{\text {th }}$ floor. The building TMD swayed twice at about 6:17 (labeled "A") and 11:53 (labeled "B"), respectively, during the typhoon. 
E-W and N-S directions on the $90^{\text {th }}$ floor were $1.26,3.35$ and $8.98 \mathrm{~cm} \mathrm{sec}^{-2}$, respectively, at $\sim 11: 53$ (UTC). Displacements, double integrated from accelerations, were estimated to be $0.26,4.71$, and $9.04 \mathrm{~cm}$ in the vertical, E-W and N-S directions, respectively.

The data presented in Fig. 2 from the TBA are quite complicated. To retrieve significant information provided by the TBA, data must be processed carefully. DC-offset was eliminated by subtracting the mean amplitude from the raw data. The data were divided into 24 one-hour time intervals and each time interval was again subdivided into eighteen 204.8-sec non-overlapping windows. The data of each window were Hamming tapered and then subject to a fast Fourier-transform. The Fourier amplitude spectra were not smoothed in each window. The spectra of the eighteen windows were averaged to form the spectra of an hour, thus reducing the variance. This produced 24 one-hour spectra. The frequencies associated with the peak amplitudes of each one-hour spectrum were almost identical among the 24 onehour spectra, although the peak amplitudes changed from one spectrum to another. Figure 3 clearly demonstrates similar patterns of spectra and same frequencies with local peak amplitudes for the 24 one-hour spectra of building vibrations at T1S2 along three components. Hence, the 24 one-hour spectra estimated from the records of 19 September 2010 were further averaged to obtain the hourly spectra. In order to obtain the same scale, two acceleration spectra at the $90^{\text {th }}$ floor were divided by the angular frequency to produce the velocity spectra. The velocity spectra in the frequency range from 0.05 to $8 \mathrm{~Hz}$ along three components on 19 September 2010 are demonstrated in Fig. 4. Note that the spectral amplitudes are relatively significant because they are obtained from stacked data. In spite of the differences in amplitudes, the frequencies with the local peak amplitudes are almost identical along the three components. Obviously, the maximum spectral amplitude is $918.38 \mathrm{~cm}$ at $\mathrm{f}_{0}=0.15 \mathrm{~Hz}$. The higher modes of vibrations below $2 \mathrm{~Hz}$ appear at $\mathrm{f}_{1}=$ $0.23, \mathrm{f}_{2}=0.43, \mathrm{f}_{3}=0.58, \mathrm{f}_{4}=0.78, \mathrm{f}_{5}=1.03, \mathrm{f}_{6}=1.25, \mathrm{f}_{7}=$ 1.62 , and $\mathrm{f}_{8}=1.90 \mathrm{~Hz}$. The higher modes with $\mathrm{f}>2 \mathrm{~Hz}$ cannot be easily delineated. (a)

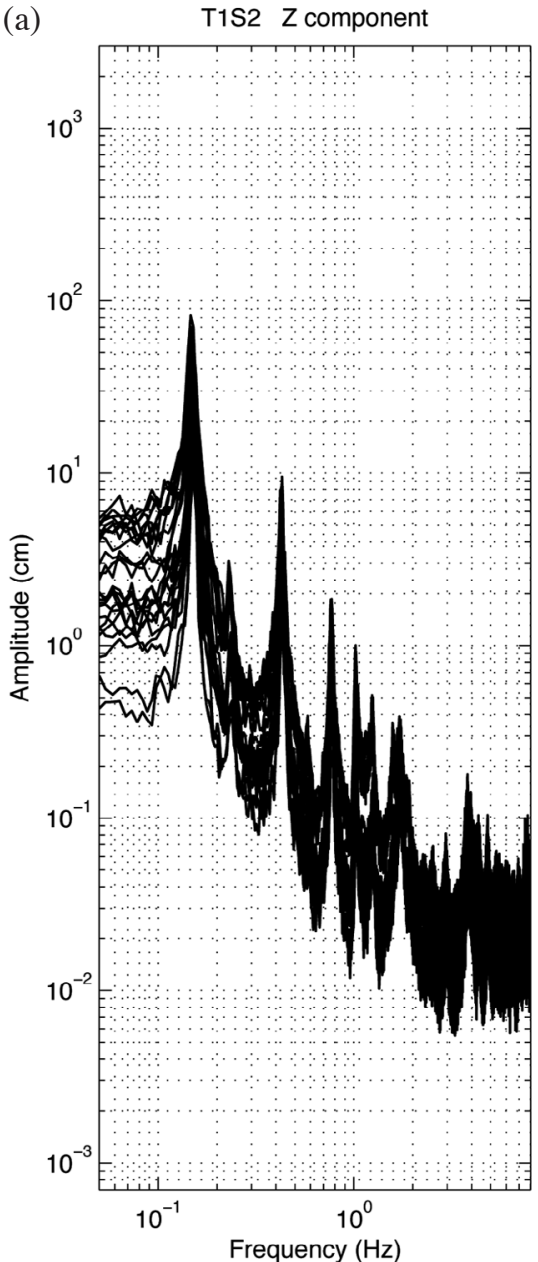

(b)

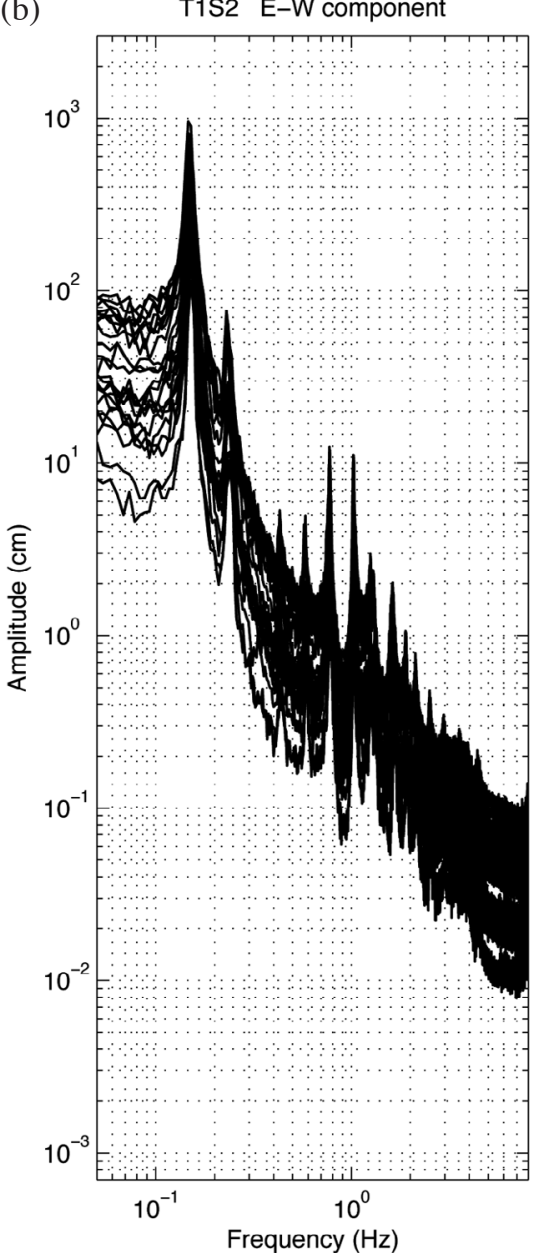

(c)

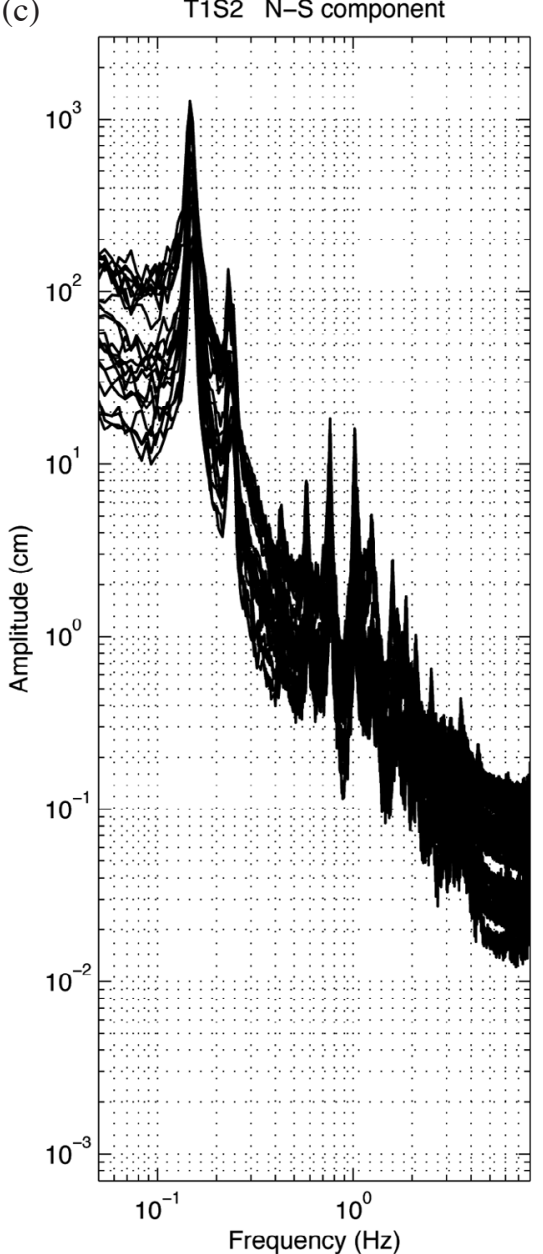

Fig. 3. Twenty-four one-hour spectra of building vibrations at T1S2: (a) for the Z component, (b) for the E-W component, and (c) for the N-S component. 
(a)

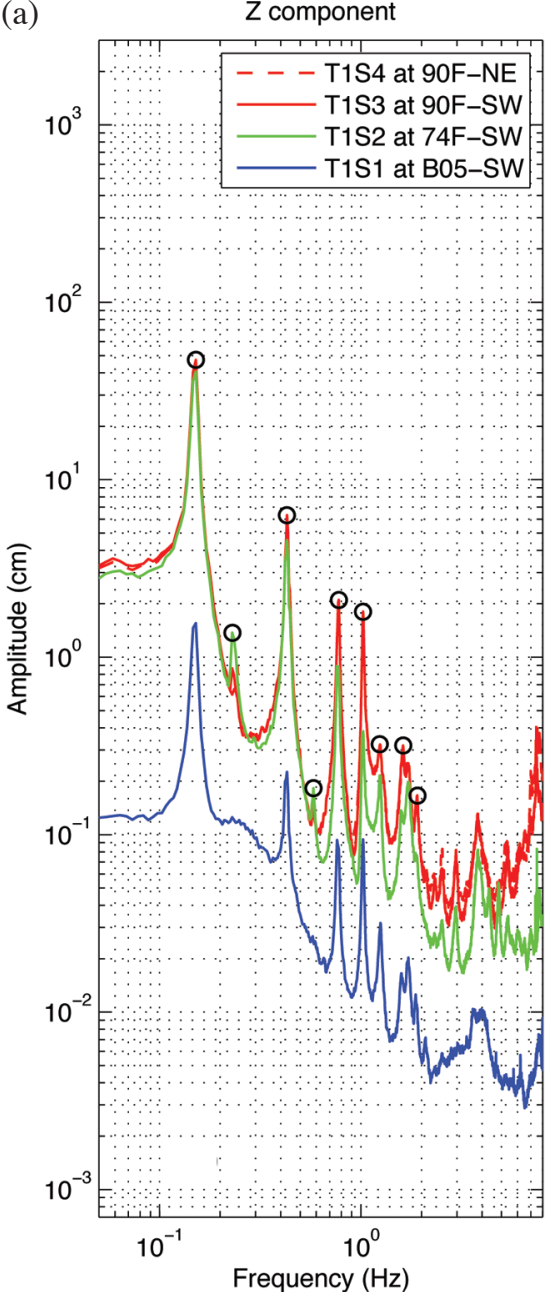

(b)

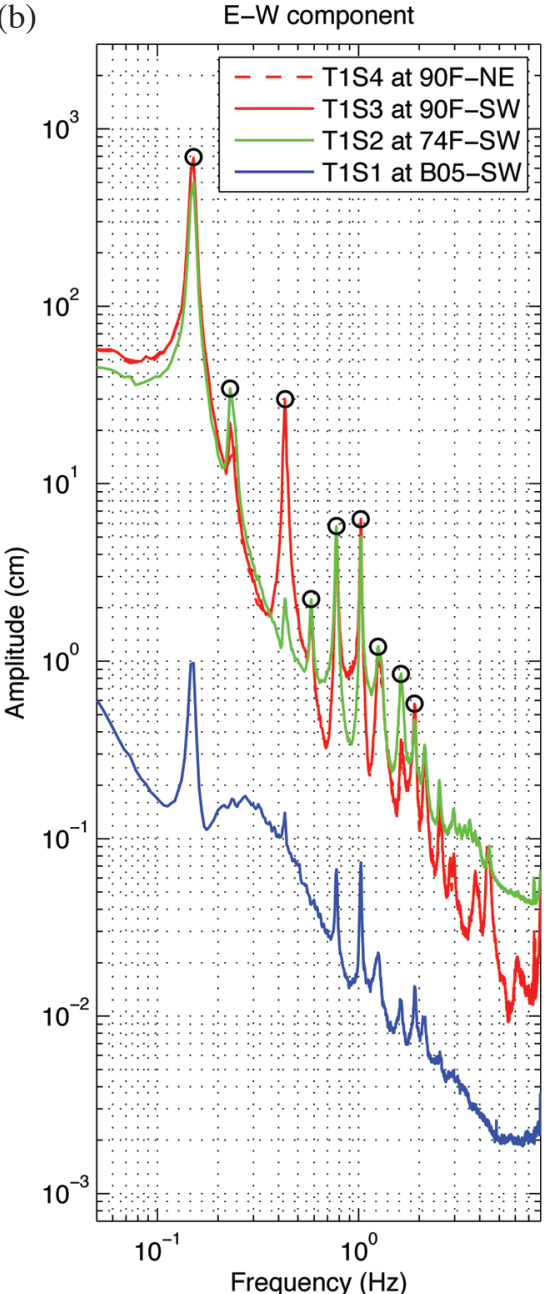

(c)

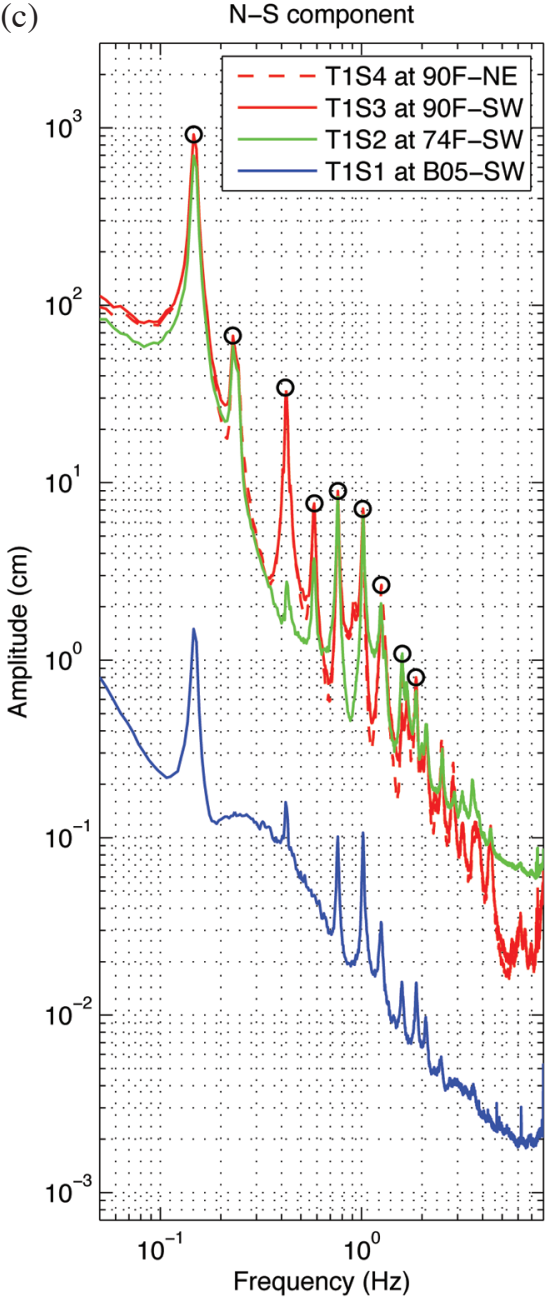

Fig. 4. Spectral amplitudes of building vibrations: (a) for the $\mathrm{Z}$ component, (b) for the E-W component, and (c) for the N-S component. The spectra at different stations are shown by lines with distinct colors. Several vibration modes with the local peak amplitudes are denoted by open circles.

When buildings are subjected to strong winds or earthquake ground shaking, torsional (rotational) vibrations (or rotation about the vertical axis) will be produced in addition to translational vibrations. Figure 5 shows the accelerations at T1S4 and rotational motions at T1S4R of the TAIPEI 101 skyscraper induced by the 2010 Typhoon Fanapi on the northeast corner of the $90^{\text {th }}$ floor. The accelerations along the two horizontal components were larger than those along the vertical component. The maximum peak ground acceleration was about $8.8 \mathrm{~cm} \mathrm{sec}^{-2}$ on the NS component at T1S4. On the contrary, the rotational motions along the vertical component were larger than those along the two horizontal components. The maximum rotational motion was about $3.7 \times 10^{-4} \mathrm{rad} \mathrm{sec}^{-1}$ on the vertical component at T1S4R. The rotational motions (Fig. 5b) during the typhoon were relatively low in comparison with the translational motions (Fig. 5a).

The spectral amplitudes of accelerations and rotational motions in the frequency range from 0.05 to $8 \mathrm{~Hz}$ along the three components on the northeast corner of the $90^{\text {th }}$ floor are shown in Fig. 6. The spectral patterns of accelerations along the three components were very similar, except for a fact that the spectral amplitudes along the two horizontal components were larger than those along the vertical component (Fig. 6a). The maximum spectral amplitude for each component appears at $\mathrm{f}_{0}=0.15 \mathrm{~Hz}$, which is almost the natural frequency of the skyscraper (Haskett et al. 2003). The local peak amplitudes along the three components at related frequencies can be clearly delineated. The values of peak amplitudes along the three components and their related frequencies are displayed in Table 1. For the torsional vibrations as shown in Fig. 6b, the maximum spectral amplitude appears at $\mathrm{f}=0.23 \mathrm{~Hz}$, which is the fundamental mode of torsional vibrations. It should be noted that a smaller spectral amplitude of torsional vibrations on the vertical component appears at $0.15 \mathrm{~Hz}$, which is consistent with the fundamental mode of translational vibrations. In spite of the differences in amplitudes, the torsional frequencies with the 
local peak amplitudes appear at $0.15,0.23,0.42,0.58,0.78$, $0.91,1.02$ and $1.30 \mathrm{~Hz}$.

\section{DISCUSSION}

In Fig. 4, several major vibration modes, each with local-peak amplitude, can be delineated. The maximum spec- tral value appears at $\mathrm{f}_{0}=0.15 \mathrm{~Hz}$, which is the frequency of fundamental mode and also the natural frequency (or the natural period of $6.8 \mathrm{sec}$ ) of the building TMD (Haskett et al. 2003), for the three components at T1S1, T1S2, $\mathrm{T} 1 \mathrm{~S} 3$, and T1S4. The spectral amplitudes for the fundamental mode at T1S2, T1S3, and T1S4 are almost equal along each of the three components. The peak spectral amplitudes

19-Sept.-2010 Typhoon Fanapi

(a)

Acceleration records of building vibrations

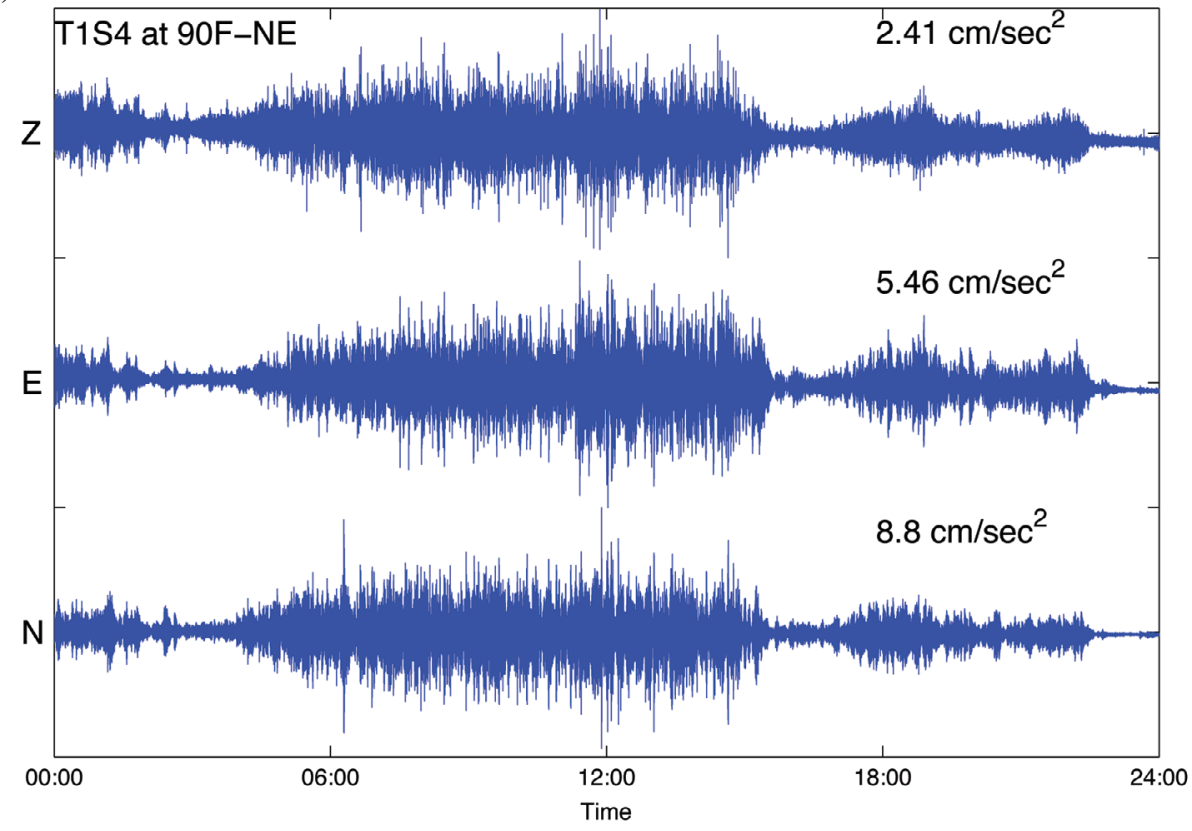

(b)

Rotation records of building vibrations

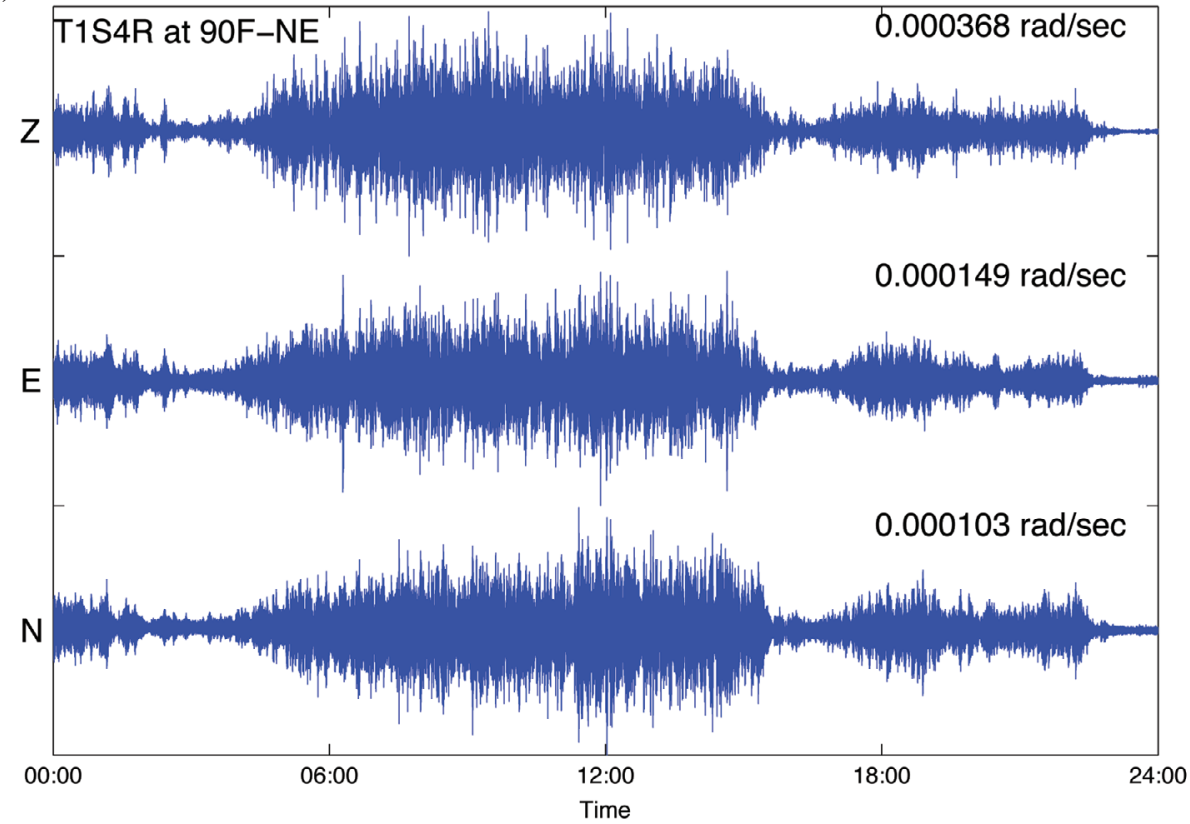

Fig. 5. Three-components records of building vibrations caused by Typhoon Fanapi: (a) for accelerations and (b) for the rotations on the northeast corner of the $90^{\text {th }}$ floor. 
(a) Fourier spectrum of acceleration induced by the 2010 Typhoon Fanapi
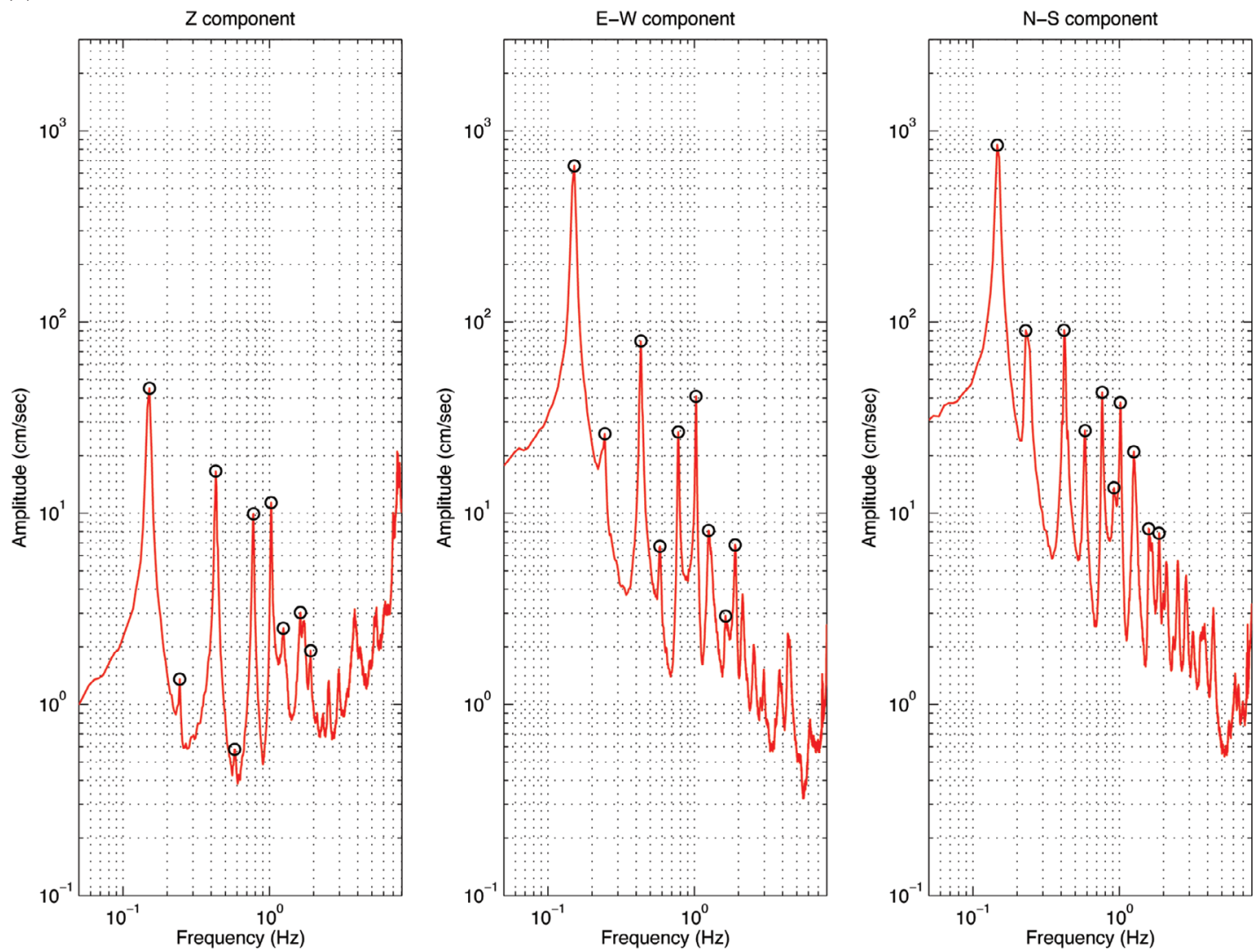

(b)

Fourier spectrum of rotation induced by the 2010 Typhoon Fanapi
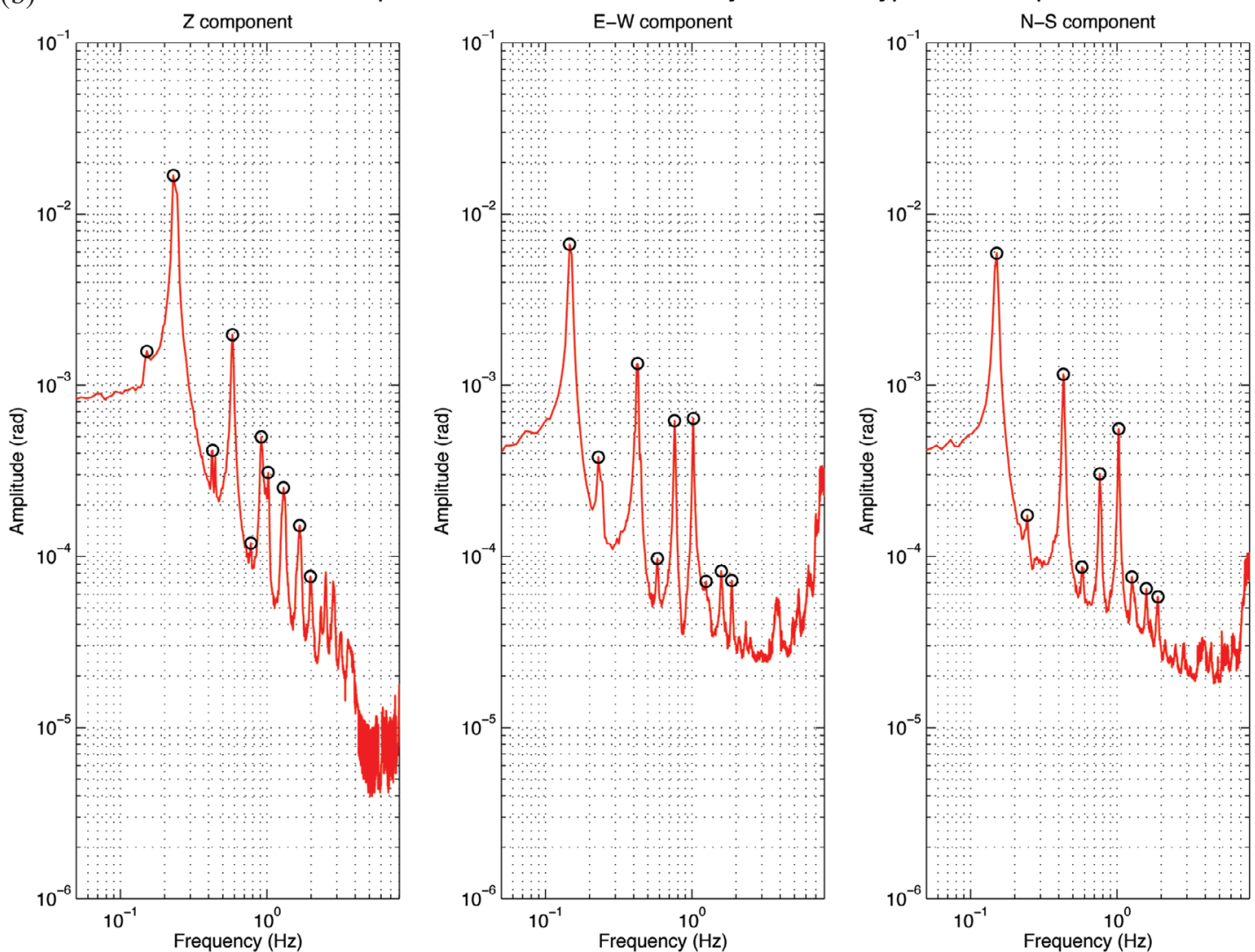

Fig. 6. Spectral amplitudes of (a) accelerations and (b) rotation motions induced by the 2010 Typhoon Fanapi on the northeast corner of the $90^{\text {th }}$ floor. Several vibration modes with respective local peak amplitudes are denoted by open circles. 
Table 1. The values of peak amplitudes along the three components $\left(A_{Z i}, A_{E W i}\right.$, and $\left.A_{N S i}\right)$ and their related frequencies $\left(f_{i}, i=0,1,2\right.$, ..., 9) at station T1S4 and T1S4R.

\begin{tabular}{|c|c|c|c|c|c|c|c|c|c|c|c|c|}
\hline \multirow{3}{*}{$\mathbf{i}$} & \multicolumn{6}{|c|}{ Acceleration (T1S4) } & \multicolumn{6}{|c|}{ Rotation motion (T1S4R) } \\
\hline & \multicolumn{2}{|c|}{$\mathbf{Z}$} & \multicolumn{2}{|c|}{ E-W } & \multicolumn{2}{|c|}{ N-S } & \multicolumn{2}{|c|}{$\mathbf{Z}$} & \multicolumn{2}{|c|}{ E-W } & \multicolumn{2}{|c|}{ N-S } \\
\hline & $\mathbf{f}_{\mathrm{i}}$ & $\mathbf{A}_{\mathrm{Zi}}$ & $\mathbf{f}_{\mathrm{i}}$ & $\mathbf{A}_{\text {EWi }}$ & $\mathbf{f}_{\mathrm{i}}$ & $\mathbf{A}_{\mathrm{NSi}}$ & $\mathbf{f}_{\mathrm{i}}$ & $\mathbf{A}_{\mathrm{zi}}$ & $\mathbf{f}_{\mathrm{i}}$ & $\mathbf{A}_{\text {EWi }}$ & $\mathbf{f}_{\mathrm{i}}$ & $\mathbf{A}_{\mathrm{NSi}}$ \\
\hline 0 & 0.151 & 44.89 & 0.151 & 656.12 & 0.147 & 843.72 & 0.151 & 0.00158 & 0.146 & 0.00665 & 0.151 & 0.00592 \\
\hline 1 & 0.244 & 1.35 & 0.244 & 26.05 & 0.230 & 90.32 & 0.229 & 0.01678 & 0.230 & 0.00038 & 0.244 & 0.00017 \\
\hline 2 & 0.430 & 16.59 & 0.430 & 79.43 & 0.420 & 90.45 & 0.425 & 0.00041 & 0.425 & 0.00134 & 0.430 & 0.00116 \\
\hline 3 & 0.576 & 0.58 & 0.581 & 6.72 & 0.581 & 27.01 & 0.581 & 0.00197 & 0.581 & 0.00010 & 0.576 & 0.00009 \\
\hline 4 & 0.776 & 9.94 & 0.776 & 26.54 & 0.762 & 42.96 & 0.776 & 0.00012 & 0.762 & 0.00062 & 0.762 & 0.00030 \\
\hline 5 & - & - & - & - & 0.918 & 13.56 & 0.913 & 0.00050 & - & - & - & - \\
\hline 6 & 1.025 & 11.34 & 1.025 & 40.79 & 1.016 & 37.91 & 1.021 & 0.00031 & 1.021 & 0.00064 & 1.025 & 0.00056 \\
\hline 7 & 1.245 & 2.50 & 1.250 & 8.13 & 1.255 & 20.94 & 1.299 & 0.00025 & 1.250 & 0.00007 & 1.265 & 0.00008 \\
\hline 8 & 1.626 & 3.02 & 1.631 & 2.90 & 1.587 & 8.32 & 1.670 & 0.00015 & 1.582 & 0.00008 & 1.587 & 0.00007 \\
\hline 9 & 1.904 & 1.91 & 1.895 & 6.83 & 1.865 & 7.87 & 1.987 & 0.00008 & 1.870 & 0.00007 & 1.899 & 0.00006 \\
\hline
\end{tabular}

are the largest, the second largest, and the smallest, respectively, for the NS-, EW-, and vertical components. For the higher modes of vibrations, on the contrary, the spectral amplitudes at T1S2, T1S3, and T1S4 vary significantly from one mode to another. The horizontal spectral amplitudes are higher than the vertical ones when $\mathrm{f}<2 \mathrm{~Hz}$ while the differences in spectral amplitudes between the horizontal and vertical components are reduced. This might be due to a fact that the loading forces on the building caused by the typhoon are mainly horizontal, especially in the lower frequency regime. For the vertical component, the spectral amplitudes at T1S3 and T1S4 are slightly higher than those at T1S2. For the two horizontal components, the spectral amplitudes at T1S3 and T1S4 are slightly higher than those at T1S2 when $\mathrm{f}<2 \mathrm{~Hz}$, yet in opposition when $\mathrm{f}>2 \mathrm{~Hz}$. Although the fundamental mode at $\mathrm{f}_{0}=0.15 \mathrm{~Hz}$ apparently appears in the three components at $\mathrm{T} 1 \mathrm{~S} 1$, the amplitudes at $\mathrm{f}_{1}$ and $\mathrm{f}_{3}$ in the three components are very small and cannot be seen clearly. It should be noted that the spectral amplitudes along the three components at T1S1 are much smaller than those at T1S2, T1S3, and T1S4. This indicates that, as expected, typhoon-induced vibrations of the building were strongly attenuated underground. Soil-structure interaction may also play an important role on small vibrations on the underground level.

The spectral amplitudes of higher-mode vibrations should be smaller than those of fundamental-mode vibrations, and decrease with increasing frequency. However, the observed spectral amplitudes vary with frequency as shown in Figs. 3, 4 and 6. The vibrations observed might be a combination of translational and torsional vibrations. For the TAIPEI 101 skyscraper with 101 stories, the building has 202 translational modes and 101 torsional modes. The two building modes might be coupled (a mode that has motion contributed by other orthogonal directions) or com- pletely uncoupled. Only the first few building modes are discussed in this study. For the fundamental building mode, the maximum spectral amplitudes of translational motions on the two horizontal components (Figs. 3b, 3c, 4b, 4c, and 6a) and a small spectral amplitude of rotational motions on the vertical component (Fig. 6b) appear at $\mathrm{f}_{0}=0.15 \mathrm{~Hz}$. This indicates that the fundamental mode shows a translational vibration along the horizontal components with a small rotational vibration. Conversely, the second mode at $\mathrm{f}=0.23 \mathrm{~Hz}$ (Fig. 6b) is the fundamental mode of torsional vibration with a small translational vibration (Figs. 3b, 3c, 4b, 4c, and 6a). Figure 7 shows the variations of normalized peak amplitudes for the translational (T1S4) and torsional (T1S4R) modes on the southwest corner of the $90^{\text {th }}$ floor. It should be noted that in the first seven modes, the peak frequencies of spectral amplitudes of accelerations and rotational motions are very similar but the peak amplitudes are inversely related to each other in each pair of modes. Therefore, both the translational and torsional vibrations of the TAIPEI 101 skyscraper can be observed and identified either from spectral amplitudes of accelerations or rotational motions as shown in Fig. 7. This phenomenon can also be observed in the vibrations of the TAIPEI 101 skyscraper induced by the 2011 Tohoku, Japan earthquake (Chen et al. 2012), in which the peak amplitudes of translational and rotational motions were inversely related to each other in each pair of modes. Installation of an accelerometer and rotational seismometer at the same site of the building will improve our understanding of building vibrations.

\section{CONCLUSIONS}

This study examined the effect of strong winds generated by Typhoon Fanapi on 19 September 2010 on the super tall TAIPEI 101 skyscraper located in the Hsinyi district of 


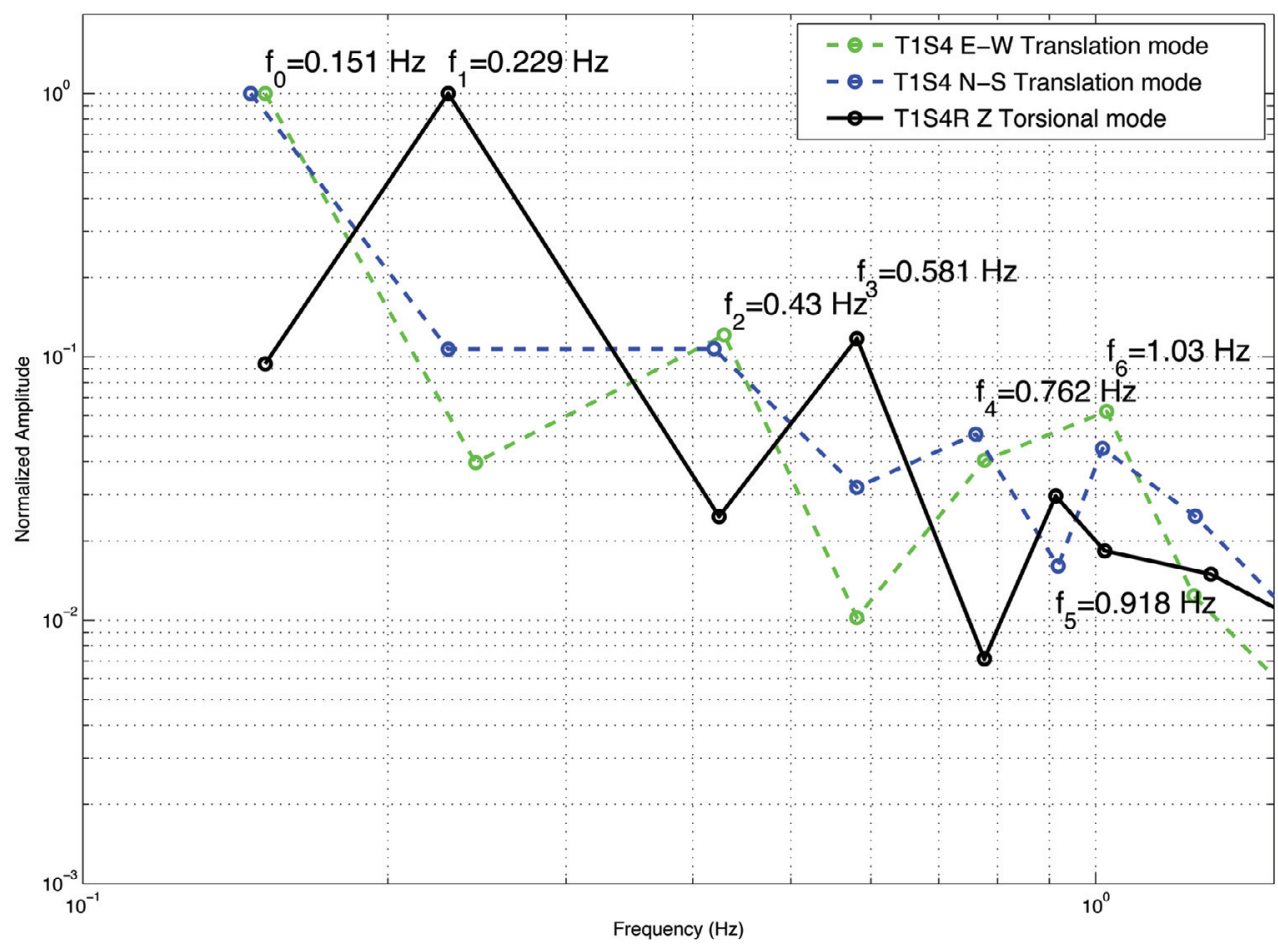

Fig. 7. Variations of the normalized peak amplitudes for the translational (T1S4) and torsional (T1S4R) modes on the northeast corner of the $90^{\text {th }}$ floor.

Taipei, Taiwan. The study examines data from a newly installed seismic building array. The skyscraper is equipped with a 660-metric-ton tuned mass damper (TMD) in the main building between the $87^{\text {th }}$ and $91^{\text {st }}$ floors. The TMD is the largest of its type in the world. Both the skyscraper and the TMD swayed during the typhoon. Maximum vertical, E-W, and N-S displacements measured on the $90^{\text {th }}$ floor were approximately $0.26,4.71$, and $9.04 \mathrm{~cm}$, respectively. In addition, the spectra of three-component seismograms recorded at the $74^{\text {th }}$ and $90^{\text {th }}$ floors above ground and the fifth floor underground were analyzed. Fundamental and higher mode vibrations, with local peak amplitudes, could be clearly seen in the spectra. The frequency of the fundamental mode was approximately $0.15 \mathrm{~Hz}$, which is the natural frequency for the skyscraper. The fundamental mode of torsional vibrations was at about $0.23 \mathrm{~Hz}$. The vibrations observed are the combination of translational and torsional vibrations. Both the translational and torsional vibrations of the TAIPEI 101 skyscraper can be observed and identified either from spectral amplitudes of accelerations or from rotational motions. This study will be of interest to building engineers who are concerned with the construction of super tall skyscrapers and the safety of building occupants and the building's contents.

Acknowledgements This paper has been benefitted greatly from the comments and suggestions by Dr. Z. K. Lee and one anonymous reviewer. We thank management of TAIPEI
101 for providing space and a power supply for the installation of the building array. We appreciate Mr. Jeff Sheu, the engineering operation manager of TAIPEI 101, for assistance in fieldwork. We also thank Mr. Chin-Shang Ku of the Institute of Earth Sciences, Academia Sinica for the assistance in the installation and maintenance of the TAIPEI 101 building array. This work was supported by the Institute of Earth Sciences, Academia Sinica and the National Science Council, ROC under grant NSC 101-2116-M-001-030.

\section{REFERENCES}

Chen, K. C., 2003: Strong ground motion and damage in the Taipei basin from the Moho reflected seismic waves during the March 31, 2002, Hualien, Taiwan earthquake. Geophys.Res.Lett.,30, 1551, doi: 10.1029/2003 GL017193. [Link]

Chen, K. C., J. H. Wang, B. S. Huang, C. C. Liu, and W. G. Huang, 2012 : Vibrations of the TAIPEI 101 skyscraper caused by the 2011 Tohoku earthquake, Japan. Earth Planets Space, 64, 1277-1286.

CWB, 2010: Available at: http://rdc28.cwb.gov.tw/data.php. eentec, 2007: R-1 Triaxial Rotational Seismometer, St. Louis, Missouri, 2 pp.

Haskett, T., B. Breukelman, J. Robinson, and J. Kottelenberg, 2003: Tuned mass dampers under excessive structural excitation. Report of the Motioneering Inc., Guelph, Ontario, Canada N1K 1B8, 7 pp. 
Hutt, C. R., J. R. Evans, and I. Yokai, 2008: A brief test of the Tokyo Sokushin VSE-355G3 strong motion velocity seismometer, Open-File Report 2008-1331, US Geological Survey, 44 pp.

Joseph, L. M., D. Poon, and S. S. Shieh, 2006: Ingredients of high-rise design TAIPEI 101, the world's tallest building. Struct. Mag., 40-45.

Kanamori, H., J. Mori, D. L. Anderson, and T. H. Heaton, 1991: Seismic excitation by the space shuttle Columbia. Nature, 349, 781-782, doi: 10.1038/349781 a0. [Link]

Kinemetrics, 2002: User Guide: EpiSensor Force Balance Accelerometer, Document 301925, Kinemetrics, Inc., $56 \mathrm{pp}$.

Li, Q. S., J. Q. Fang, A. P. Jeary, and C. K. Wong, 1998: Full scale measurements of wind effects on tall buildings. J. Wind Eng. Ind. Aerodyn., 74-76, 741-750, doi: 10.1016/S0167-6105(98)00067-1. [Link]

Li, Q. S., J. Q. Fang, A. P. Jeary, C. K. Wong, and D. K. Liu, 2000: Evaluation of wind effects on a supertall building based on full-scale measurements. Earthq. Eng. Struct. Dyn., 29, 1845-1862, doi: 10.1002/1096-9845 (200012)29:12<1845::AID-EQE995>3.0.CO;2-Q. [Link]

Li, Q. S., K. Yang, C. K. Wong, and A. P. Jeary, 2003: The effect of amplitude-dependent damping on wind-induced vibrations of a super tall building. J. Wind Eng. Ind. Aerodyn., 91, 1175-1198, doi: 10.1016/S0167-61 05(03)00080-1. [Link]

Li, Q. S., Y. Q. Xiao, C. K. Wong, and A. P. Teary, 2004:
Field measurements of typhoon effects on a super tall building. Eng. Struct., 26, 233-244, doi: 10.1016/j.engstruct.2003.09.013. [Link]

Li, Q. S., Y. Q. Xiao, and C. K. Wong, 2005: Full-scale monitoring of typhoon effects on super tall buildings. J. Fluids Struct., 20, 697-717, doi: 10.1016/j.jfluidstructs.2005.04.003. [Link]

Li, Q. S., Y. Q. Xiao, J. Y. Fu, and Z. N. Li, 2007: Full-scale measurements of wind effects on the Jin Mao building. J. Wind Eng. Ind. Aerodyn., 95, 445-466, doi: 10.1016/ j.jweia.2006.09.002. [Link]

Liu, K. S. and Y. B. Tsai, 2010: Observed natural frequencies, damping ratios, and mode shapes of vibration of a 30-story building excited by a major earthquake and typhoon. Earthq. Spectra, 26, 371-397, doi: 10.1193/ 1.3385471. [Link]

Shieh, S. S., C. C. Chang, and J. H. Jong, 2003: Structure design of composite super-columns for the TAIPEI 101 Tower. Proceeding of of International workshop on steel and concrete composite constructions, National Center for Research on Earthquake Engineering of Taiwan, 8-9 October 2003, 25-33.

Wang, Y. H., I. H. Lee, and D. P. Wang, 2005: Typhoon induced extreme coastal surge: a case study at northern Taiwan in 1994. J. Coast. Res., 21, 548-552.

Xu, Y.L. and S.Zhan, 2001: Field measurements of Di Wang Tower during Typhoon York. J. Wind Eng. Ind. Aerodyn., 89, 73-93, doi: 10.1016/S0167-6105(00)00029-5. [Link] 